\title{
Archéopages
}

Archéopages

Archéologie et société

\section{Interprétation d'un bâtiment par analyse des sols et étude carpologique}

Perrine Gambier, Véronique Zech-Matterne et Julien Avinain

\section{(2) OpenEdition}

1 Journals

Édition électronique

URL : https://journals.openedition.org/archeopages/264

DOI : 10.4000/archeopages. 264

ISSN : 2269-9872

Éditeur

INRAP - Institut national de recherches archéologiques préventives

Édition imprimée

Date de publication : 1 mai 2013

Pagination : 17

ISSN : 1622-8545

\section{Référence électronique}

Perrine Gambier, Véronique Zech-Matterne et Julien Avinain, «Interprétation d'un bâtiment par analyse des sols et étude carpologique », Archéopages [En ligne], 35 | 10/2012, mis en ligne le 01 octobre 2014, consulté le 22 janvier 2022. URL : http://journals.openedition.org/archeopages/264 ; DOI : https://doi.org/10.4000/archeopages.264 


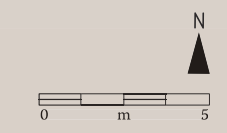

$\stackrel{N}{\Lambda}$
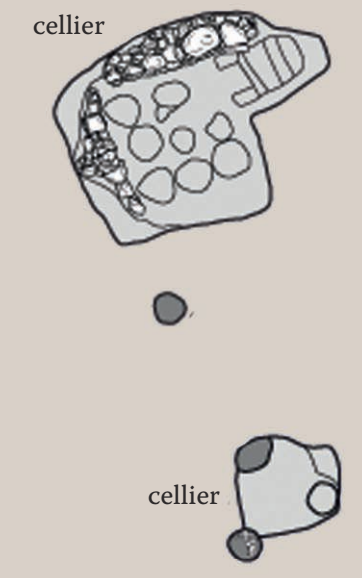

proches des champs. La diversité des adventices des cultures suggère aussi la possibilité que des sous-produits de nettoyage des grains ou des stocks non traités aient été donnés en complément alimentaire au bétail. L'importance de l'élevage sur le site suggère une gestion pour recueillir facilement le fumier, afin d'améliorer ou de maintenir la fertilité des parcelles cultivées. La prédominance du blé tendre, espèce céréalière la plus exigeante du point de vue agronomique, a certainement justifié de telles pratiques. Plusieurs espèces de graminées sont caractéristiques des sols siliceux et pourraient être indicatrices de sols plus pauvres exploités en prairies. La présence d'espèces nitrophiles (mouron rouge, ballote, renouée liseron, bardanes, patience crépue, lierre terrestre, véroniques, orties) montrent un possible amendement des champs (Jauzein, 1995). Une mise en stabulation du bétail ou son parcage au sein de corrals pouvait

faciliter le rassemblement du fumier, même si les bâtiments testés n'ont pas tous révélé des concentrations de phosphates évocatrices de telles pratiques. I'hypothèse a cependant été retenue pour le bâtiment 3 .

L'apport de l'archéozoologie dans l'identification des bâtiments d'élevage demeure limité à de rares cas : présence importante de dents de lait sur un sol conservé, ensemble anatomique entier d'animaux périnataux ou juvéniles retrouvé à proximité. Sur le site d' lès-Louvres « La Grande fosse ", les fosses attenantes au bâtiment 3 ont livré du matériel osseux animal, mais il s'agit de déchets alimentaires (traces de découpe) qui n'aident pas à identifier la fonction du bâtiment 3. Les indications d'élevage sont donc à chercher à l'échelle du site global. L'étude archéozoologique effectuée pour cette période a montré une dominance de la triade domestique bœuf, porc, capriné, sans majorité écrasante de l'une des espèces. Les restes osseux sont surtout liés à la consommation, ce qui tend à démontrer que les carcasses n'étaient pas traitées sur le site. Les animaux n'auraient pas été produits in situ en sorte que les habitants auraient été des consommateurs plutôt que des producteurs des animaux de cette triade.

Cependant, la part très importante des équidés dépasse largement la moyenne des sites ruraux (Lepetz, 1996). Les restes ne présentent pas de traces de découpes liées à une consommation. Ce fort taux a donc été rapproché d'une activité d'élevage sur le site. Ia présence de deux squelettes entiers de chevaux mâles, dans une fosse éloignée du bâtiment 3 , conforte ce raisonnement. La datation de cette structure (période gallo-romaine tardive) demeure incertaine. Les individus découverts étant particulièrement grands et robustes, on peut envisager, dans le cas où il s'agirait bien d'animaux gallo-romains, un élevage de chevaux de qualité. Une population de dimension plus modeste ayant été mise en évidence, il pourrait hypothétiquement s'agir d'animaux importés pour améliorer la population équine indigène. Ainsi, si les données archéozoologiques n'ont pas permis d'apporter de nouvelles preuve quant à l'identification du bâtiment 3, elles ont cependant mis en évidence la présence d'un important élevage équin sur le site.

Il est donc envisageable que le bâtiment 3 ait pu servir pour leur parcage.

Références bibliographiques

JAUZEIN PH., 1995, Flore des champs cultivés, Quae, 898 p LEPETZ S., 1996, «Effets de la romanisation sur l'élevage dans les établissements ruraux du nord de la Gaule l'exemple de l'augmentation de la stature des animaux domestiques », Revue archéologique de Picardie, 11, p. 317-324. 